\title{
High Pressure Effects on the Martensitic Transformations
}

\author{
V.A. Chernenko \\ Institute of Metal Physics, Vernadsky str. 36, Kiev, 252680 Ukraine
}

\begin{abstract}
The results of high hydrostatic pressure studies of martensitic transformations in alloys with special emphasis to shape memory alloys (SMA) are reviewed. Experimentally detected positive and negative signs of Ms temperature pressure shift and phase p-T diagrams are discussed. High pressure induced shape memory effect and baroelasticity are considered to be the essential phenomena illustrating the importance of pressure as a thermodynamic variable. Some estimations of high pressure influence on $\mathrm{Ms}$ temperature in framework of phenomenological Landau theory are made.
\end{abstract}

\section{INTRODUCTION}

The study of the effect of high hydrostatic pressure has contributed much to the understanding of the properties of materials near phase transformations and of the mechanisms for certain types of transformations. In addition high pressure studies have led to the discovery of a variety of new phase transformations which can only take place under pressure. Martensitic transformation (MT) is one of the most general cooperative phenomena in which the spontaneous lattice strain appearence is the main feature. Hydrostatic pressure interacts only with the diagonal components of the transformation strain tensor and allows to determine the signs and values of volume change [1] or latent heat [2] accompanying MT. Since the first works devoted to high pressure study of thermoelastic MT in $\mathrm{Cu}-\mathrm{Al}$ and Au-Cd alloys $[2,3]$ only in the past decade there has been performed such investigations of other shape memory alloys (SMA) mainly due to the efforts of Ukrainian [1-11] and Japanese researchers [12-17]. Some results were summarized in refs. [10,17]. In this paper the available information about the hydrostatic pressure studies of MT is discussed. The field still remains rather unexplored taking into account the number of alloys investigated and pressure interval used. Moreover some experimental data appeared to be contradictory. In these circumstances it is not possible to make general conclusions about the results in form of some classification. Furthermore the discussion will be 1 imited to the conventional alloys with special emphasis to SMA. For the reasons of space limitation the results of high pressure studies of MT in pure elements like Li [18] 
or Ce [19] as well as their alloys [20,21] are omitted. An attempt is also made to seek an alternative phenomenological theory to describe MT under hydrostatic pressure.

\section{EFFECT OF HYDROSTATIC PRESSURE ON MS TEMPERATURE}

Hydrostatic pressure investigations of MT up to $1.5 \mathrm{GPa}$ so far performed were carried out using mainly piston cylinder type [22] and autonomous valve high pressure chamber equipped by a special cell [23]. Diamond anvil cell generating hydrostatic pressure up to $10 \mathrm{GPa}$ was used in [13]. Thermoelastic MT's are very sensitive to the shear stresses which can appear during high pressure generation or pressure cell cooling. Therefore, it is extremely important to know exactly the nature of the applied stress. Results obtained by means of quasihydrostatic equipment (see, e.g. $[3,24]$ ) are very difficult for interpretation. So, care must be taken about the choice of the pressure transmitting mediums, kerosine and kerosine-oil mixture being used by Japanese researchers and silicone oil or benzene being used by Ukrainian researchers. In [25] it was shown that the latter liquids have better hydrostatic properties than former in pressure interval up to 1 GPa and temperature range down to $4.2 \mathrm{~K}$. According to [25] ethylmethyl alcohols mixture used in diamond anvil type apparatus [13] did not provide the proper hydrostatic conditions.

The first step of high pressure study of any phase transformation is the determination of its $P-T$ diagram, $i . e$. pressure dependence of equilibrium transformation temperature, To. Actually the Ms, Mf, As, Af temperatures can be extracted from the experimental data, and some doubts about the pressure behaviour of To always exist. If high pressure does not distort the shape of hysteresis loops on the temperature dependence of some physical property but shifts it as a whole along the temperature axis, it is reasonable to assume that both $M s(p)$ and To(p) dependences have identical behaviour. Electrical resistivity, $\rho,\left(A u C d, T i N i-, C u_{3} A l-\right.$ and Fe-based alloys) and low field magnetic susceptibility, $\chi$, measurements ( $\mathrm{Ni}_{2} \mathrm{MnGa}-$ and Fe-based alloys) were performed under high pressure [1- 17] in order to determine the pressure shift of Ms. It is required that Ms values must be chosen in the same manner for each pressure level used. The results are presented in Table 1 (the early works devoted to high pressure investigations of irreversible MT in Fe-based alloys and published before 1971 were reviewed in [26]). It turned out that Ms(p) dependences can be approximated by straight lines for all alloys except binary Fe-Pt and Fe-Ni alloys. The initial dMs/dp values were calculated and displayed in Table 1. Some comments and remarks to Table 1 are given below.

2.1. TiNi and Cu-based alloys

Among TiNi-based alloys Ti50Ni47Fe3 was studied first under high pressure[4]. This alloy was the most suitable for investigation of $B 2-R$ and R-B19' transformations because the two transformations are separated by $100 \mathrm{~K}$ on the temperature scale.The opposite slope signs of Ms(p) and $T_{R}(p)$-lines were found revealing pressure induced broadening of $R-$ phase area on $\mathrm{p}-\mathrm{T}$ diagram.Following clausius-clapeyron relationship $\mathrm{dMs} / \mathrm{dp}=\Delta \mathrm{V} / \Delta \mathrm{S}=\mathrm{T} \Delta \mathrm{V} / \mathrm{Q}$

$(\Delta \mathrm{V}$ and $\Delta \mathrm{S}$ are the discontinuities in the volume and entropy at the transformation and $Q$ is the latent heat) and according to the data from $[4,27]$ one can estimate $\Delta V / V$ values being equal to $-0.04 \%$ and $0.5 \%$ for $\mathrm{B} 2-\mathrm{R}$ and $\mathrm{R}-\mathrm{B} 19^{\prime}$ transformations, respectively. The situation is more complicated in case of binary TiNi alloys, where it is known that both mentioned MT's and the additional B2 - B19' transformation 
are superimposed. The measurements in Ti51Ni49 alloy showed [10] that applied pressure led to the reversible widening and growth of belllike anomaly on $\rho(\mathrm{T})$ curve. One of the possible explanation of such Table 1 Characteristics of martensitic transformations (Ms - transformation temperature, $\Delta \mathrm{T}$-thermal hysteresis, aMs/dp-Ms pressure shift).

No. Alloy

Transformation

$\mathrm{Ms}, \mathrm{K} \underset{\mathrm{K}}{\Delta \mathrm{T}} \underset{\mathrm{K} / \mathrm{GPa}}{\underset{\mathrm{C}}{(\mathrm{dMs}} / \mathrm{dp}} \mathrm{p}_{=0}^{\text {Ref. }}$

\begin{tabular}{|c|c|c|c|c|c|c|}
\hline & Thermoelastic martens & itic transform & atio & & & \\
\hline 1 & $\mathrm{Au}-47.5 \mathrm{~cd}$ (at. $\%$ ) & B2 $-\zeta^{\prime}$ & 333 & 15 & 20 & [2] \\
\hline 2 & $\mathrm{Ti}-47 \mathrm{Ni}-3 \mathrm{Fe}(\mathrm{at} . \%)$ & $B 2-R^{2}$ & 270 & 3 & 4.5 & [4] \\
\hline & & $R-B 19^{\prime}$ & 160 & 55 & -17 & [4] \\
\hline 3 & $\mathrm{Ti}-49 \mathrm{Ni} \quad$ (at. $\%$ ) & $B 2-R$ & 340 & & 4.5 & [10] \\
\hline 4 & Ti-51Ni (at. $\%$ ) "short aged" & $\mathrm{B} 2-\mathrm{R}$ & 300 & 75 & 0 & [15] \\
\hline & & $R-B 19^{\prime}$ & 187 & 4 & 10 & [15] \\
\hline & Ti-51Ni(at. $\%$ ) "long aged" & B2 - R & 297 & & 0 & [15] \\
\hline & & $R-B 19$ & 270 & & 0 & [15] \\
\hline 5 & $\mathrm{Ni}-24.2 \mathrm{Mn}-26 \mathrm{Ga}$ (at. $\%$ ) & $\mathrm{C}(\mathrm{L} 2,1)-\mathrm{BCT}(5 \mathrm{M})$ & 175 & 25 & 6 & [5] \\
\hline 6 & $\mathrm{Cu}-12 \mathrm{Al}-5.1 \mathrm{Mn}(\mathrm{wt} . \circ)$ & $\beta_{1}^{\prime}-\beta_{1}^{\prime}$ & 275 & 16 & 6 & {$[6]$} \\
\hline 7 & $C u-13.5 \mathrm{Al}-5 \mathrm{Ni} \quad(w t . \%)$ & $\beta_{1}-\beta_{1}^{\prime}$ & 321 & 7 & 4.3 & {$[7]$} \\
\hline 8 & $\mathrm{Cu}-13.5 \mathrm{Al}-4.5 \mathrm{Ni}$ (wt. $\frac{\circ}{8}$ ) & $\beta_{1}-\beta_{1}^{\prime}$ & 359 & 11 & 6 & [7] \\
\hline 9 & $\mathrm{Cu}-14.7 \mathrm{Al}-4.2 \mathrm{Ni}$ (wt. $\left.\frac{\circ}{6}\right)$ & $\beta_{1}-\beta_{1}^{\prime}$ & 277 & 9 & 5 & [13] \\
\hline 10 & $\mathrm{Cu}-14 \mathrm{Al}-2 \mathrm{Ni}$ (wt. $\left.\frac{\%}{\%}\right)$ & $\beta_{1}-\gamma_{1}^{\prime}$ & 312 & 32 & $-7 \cdot 1$ & {$[7]$} \\
\hline 11 & $\mathrm{Cu}-14.5 \mathrm{Al}-4.5$ (wt. $\%)$ & $\beta_{1}-\gamma_{1}^{\prime}$ & 113 & 40 & -6 & {$[7]$} \\
\hline 12 & $\mathrm{Cu}-14.5 \mathrm{Al}-3.5 \mathrm{Ni}$ (wt. $\left.\frac{\circ}{8}\right)$ & $\beta_{1}-\gamma_{1}^{\prime}$ & 240 & 37 & 5 & [13] \\
\hline 13 & $\mathrm{CU}-\mathrm{Al}-\mathrm{N} \mathrm{i}$ & $\beta_{1}-\gamma_{1}^{\prime}$ & 230 & 37 & -10 & [1] \\
\hline $\begin{array}{l}14 \\
15\end{array}$ & $\begin{array}{l}\mathrm{Fe}-21 \mathrm{Ni}-28 \mathrm{Co}-6 \mathrm{Ti} \text { (wt. \%) } \\
\mathrm{Fe}-30.5 \mathrm{NT}-19 \mathrm{Co}-5 \mathrm{Ti} \text { (wt. \%) }\end{array}$ & $\begin{array}{l}\mathrm{FCC}-\mathrm{BCT} \\
\mathrm{FCC}-\mathrm{BCT}\end{array}$ & 318 & $\begin{array}{r}110 \\
27\end{array}$ & -40 & $\begin{array}{l}{[8]} \\
{[8]}\end{array}$ \\
\hline 16 & Fe-31.9Ni-9.8Co-4.1Ti (at. $\left.\frac{1}{6}\right)$ & $F C C-B C T$ & $\begin{array}{l}250 \\
113\end{array}$ & 22 & $\begin{array}{l}-63 \\
-90\end{array}$ & [15] \\
\hline 17 & $\mathrm{Fe}-28.5 \mathrm{Ni}-18.9 \mathrm{Co}-6.3 \mathrm{Ti}$ (wt. $\%$ ) & $\mathrm{FCC}-\mathrm{BCT}$ & 155 & 60 & -70 & [11] \\
\hline 18 & $\mathrm{Fe}-24 \mathrm{Pt} \quad(\mathrm{at} . \%) \mathrm{s}=0$ & FCC - BCT & 287 & 60 & -20 & [16] \\
\hline & $S \cong 0.6$ & $\mathrm{FCC}\left(\mathrm{LI}_{2}\right)-\mathrm{BCT}$ & 200 & 20 & 0 & [16] \\
\hline & $S \cong 0.8$ & $\mathrm{FCC}\left(L 1_{2}^{2}\right)-\mathrm{BCT}$ & 173 & 18 & 34 & {$[17]$} \\
\hline & Irreversible m & artensitic tra & nsfo & & & \\
\hline 19 & $\mathrm{Fe}-29.9 \mathrm{Ni}$ (at.\%) & $\gamma-\alpha$ & 213 & & -34 & [12] \\
\hline 20 & $\mathrm{Fe}-24.6 \mathrm{Ni}-1.8 \mathrm{C}$ (at. $\%$ ) & $\gamma-\alpha$ & 223 & & -60 & {$[12]$} \\
\hline 21 & $\mathrm{Fe}-18.6 \mathrm{Ni}-3.6 \mathrm{C}$ (at. $\%$ ) & $\gamma-\alpha$ & & & -72 & [17] \\
\hline 22 & $\mathrm{Fe}-28.6 \mathrm{Ni}-1.4 \mathrm{C}$ (at. $\%)$ & $\gamma-\alpha$ & & & -40 & {$[17]$} \\
\hline 23 & $\mathrm{Fe}-28.5 \mathrm{Ni}$ (wt. $\%)$ & $-\alpha$ & 245 & & -72 & [11] \\
\hline 24 & $\mathrm{Fe}-22 \mathrm{Ni}-28.7 \mathrm{Co}(\mathrm{wt} . \%)$ & $\gamma-\alpha$ & 239 & & -18 & [11] \\
\hline 25 & $\mathrm{Fe}-28.9 \mathrm{Ni}-9.5 \mathrm{CO}$ (wt. $\%$ ) & $\gamma-\alpha$ & 227 & & -32 & [11] \\
\hline
\end{tabular}

behavior could be understood taking into account the positive pressure shift of Ms for the B2 - B19' MT that is confirmed by the negative sign of $\Delta V / V$ given in [28]. The essential influence of alloy composition on dMs/dp values and signs in binary TiNi alloys as well as Cubased alloys is seen in Table 1. This preliminary conclusion has to be proved in future.

2.2.Ni2MnGa.

There has been much recent progress in the study of the ferromagnetic Heusler alloy $\mathrm{Ni}_{2} \mathrm{MnGa}$, having perfect shape memory effect (SME) [29]. As to high pressure results one can estimate from (1) that $\Delta V / V$ for $M T$ 
from parent phase into five-layered modulated martensitic structure is equal to about $-0.05 \%$ [10] which is too small compared with value being directly obtained from lattice spacings [30]. In this connection both lattice spacings and latent heat should be specified.

2.3. Fe-based alloys.

Ferrous alloys and steels undergoing thermoelastic and irreversible MT in ferromagnetic austenite (alloys 14-19, 22-25) or in paramagnetic (noninvar alloys 21,22 ) have received much attention from viewpoint of high pressure studies (Table 1). While in $[8,11]$ it was shown experimentally the linear decreasing of Ms(p) for invar-type alloys $15,16,23-25$ in the pressure interval studied, in $[12,16,17]$ there was observed another picture: smaller initial slope of Ms(p) curve was changed by a sharper decrease of Ms at higher pressures. The reason for such behaviour is attributed in $[12,14]$ to pressure effect on magnetovolume properties. According to Table 1 dMs/dp becomes smaller with the increase of co content disregarding whether non- or thermoelastic MT occurs. As was shown in [11] this is a consequence of the $\Delta \mathrm{V} / \mathrm{V}$ decrease from $2.1 \%$ (alloy 23) to $0.2 \%$ (alloy 24) due to co addition in FeNi-alloys. Another interesting feature found in [26] is the correlation between atomic ordering degree of Fe-Pt alloy and the kind of $\mathrm{P}-\mathrm{T}$ diagram, where a small maximum was detected.

\section{LANDAU-TYPE THEORY}

Usually the data concerning the Ms(p) behavior were phenomenologically interpreted in framework of equation (1) or modified expression $[12,13]$. In this section an attempt will be made to propose Landautype theory for the description of MT's under high pressure, which are accompanied by corresponding symmetry changes. Gibbs free energy expansion for cubic crystal having up to fourth-order invariants and two component strain order parameter $\left(\eta_{1}, \eta_{2}\right)$ [31] can be completed by pressure and volume containing terms and written as:

$$
\begin{aligned}
\mathrm{G}= & \frac{\alpha}{2}\left(\eta_{1}^{2}+\eta_{2}^{2}\right)+\frac{\beta}{3} \eta_{1}\left(\eta_{1}^{2}-3 \eta_{2}^{2}\right)+\frac{\gamma}{4}\left(\eta_{1}^{2}+\eta_{2}^{2}\right)^{2}+\frac{\delta}{2} \eta_{0}\left(\eta_{1}^{2}+\eta_{2}^{2}\right)+\frac{3}{2} \eta_{0}^{2}+\frac{\xi^{3}}{3} \eta_{0}^{3}+\frac{\theta}{4} \eta_{0}^{4}+ \\
& +\frac{\zeta}{2} \eta_{0}^{2}\left(\eta_{1}^{2}+\eta_{2}^{2}\right)+3 p \eta_{0}
\end{aligned}
$$

Here $\alpha^{\prime}=\alpha[T-T o(0)], \alpha^{\prime}=\left(C_{11}-C_{12}\right) / 6, k=C_{11}+2 C_{12}$ and $\alpha, \beta, \gamma, \delta$, $\zeta, \theta, \xi$ are coefficients, $\eta_{0}$-strain corresponding to a volume change at the transformation, $\Delta V / V=3 \eta_{0}$. The strain tensor components for a cubic crystal are expressed as: $\eta_{0}=\left(\eta_{11}+\eta_{22}+\eta_{33}\right) / 3, \eta_{1}=2 \eta_{33}-\eta_{22}-\eta_{11}$, $\eta_{2}=\left(\eta_{11}-\eta_{22}\right) / \sqrt{3}$, where $\eta_{i i}$ is a component of the Lagrangian strain tensor. For the cubic - tetragonal transformation it may be shown that $G$ is minimized when:

$$
\begin{aligned}
& \eta_{1}=\eta_{2}=0, \eta_{0} \cong-p / k \text { for parent phase } \\
& \eta_{2}=0, \eta_{1}=u_{0}=-\left[1+\left(1-4 \gamma \alpha^{\prime} / \beta^{2}\right)^{1 / 2}\right] \beta / 2 \gamma
\end{aligned}
$$

for $z$ - domain of martensitic phase,

$$
\eta_{0} \cong-\left(3 p+\delta u_{0}^{2} / 2\right) / 3 k
$$

It follows from (5) that sign $\delta=-\operatorname{sign} \Delta V$. Inspection of (2) by inserting (3) with respect to the transformation conditions provides the pressure shift of To in the form: 
$T_{0}(p)=T_{0}(0)+\frac{--1}{\alpha\left(C_{11}+2 C_{12}\right)}\left[\begin{array}{c}C_{11}+2 C_{12} \\ C_{12}\end{array}\right.$

Expression (6) predicts two types of p-T diagrams:(i) if $\delta<0$ To (p) $<0$ (0); (ii) in case $\delta>0$ it is expected a maximum on the To(p) curve. According to [31] $\delta=\left(C_{111}-C_{123}\right) / 12, \zeta$ is a function of four-order elastic constants. Estimates for $\mathrm{Ni}_{2} \mathrm{MnGa}$ exhibiting cubic-tetragonal MT can not be done using $(6)$ because $\delta$ and $\zeta$ are unknown. As soon as the experiment show linear dependence of $T o(p)$ the last quadratic term in (6) can be omitted and the To(p) dependence for $\mathrm{Ni}_{2}$ MnGa can be rewritten as $T o(p)-T o(0) \cong k p$, where

$$
\kappa \cong(1 / 2 \alpha)\left[\left(V_{A}-v_{M}\right) / V_{A}\right]\left[a_{A} /\left(c_{M}-a_{M}\right)\right]^{2}
$$

For $z$ - domain $u_{0}=2\left(\eta_{33}-\eta_{11}\right)=2\left(c_{M}-a_{M}\right) / a_{A}$. Calculation using ultrasonic data [29] gives $\alpha \cong 0.7610^{9} \mathrm{dyn} / \mathrm{cm}^{2} \mathrm{~K}, a_{i}, v_{i}$ - lattice

parameters and specific volume of parent and martensitic phases respectively. According to (7) $\kappa \cong 34 \mathrm{~K} / \mathrm{GPa}$, which is about six times higher than the experimental value (Table 1). Apparently the value of $\Delta \mathrm{V} / \mathrm{V}$ for $\mathrm{Ni}_{2} \mathrm{MnGa}$ given in [30] is too high and should be corrected.

Thus Landau-type theory can be useful in understanding high pressure behaviour of martensitic transformations.

\section{BAROELASTICITY EFFECT}

One of the remarkable results of high pressure influence on the thermoelastic MT's was the discovery that high hydrostatic pressure stimulated reversible shape change of SMA's. This effect was firstly experimentally observed on alloy 15 [9], which was the most suitable for investigating this effect due to the large slope of Ms(p) curve and appropriate Ms value. The pressure induced reversible bending of a plate-like sample, loaded according to the scheme of the three-point deflection was measured [9]. This effect was caused by reversible "martensite-austenite" boundary motion under pressure (baroelasticity). Incidentally, the pressure induced growth and shrinkage of martensite plates in alloy 9 was found in [13] using insitu optical microscopy and diamond anvil pressure cell. Thus, the baroelastic behaviour is supposed to be a general property of all thermoelastic MT's except in cases in which new pressure-induced phases on $\mathrm{p}-\mathrm{T}$ diagram appear.

\section{ConClusions}

In this paper some problems of high hydrostatic pressure study of MT's were reviewed. As known from the above analysis some experimental results appeared to be discouraged and they need a further verification. Undoubtedly the phenomenological approach based on Landau-type theory is a useful means in predicting hydrostatic pressure data and should be developed for other MT's. Baroelasticity phenomenon was outlined in order to show that hydrostatic pressure is a new force to operate shape memory effect.

\section{ACKNOLEDGEMENTS}

Author is grateful to Kokorin V.V. for stimulating discussions and to $L^{\prime}$ vov V.A. for his cooperation on theoretical treatment of MT's.

\section{REFERENCES}

[1] Lushankin I.V., Martynov V.V., Khandros L.G., Chernenko V.A., Metallofizika 6 (1984) 93-94. 
[2] Gefen Y., Halwany A., Rosen M., Phil. Mag. 28 (1973) 1-9.

[3] Brettschneider I. and Warlimont H., Z. Metallkde. 59 (1968) $740-749$.

[4] Zakrevskiy I.G., Kokorin V.V., Chernenko V.A., Kachalov V.M., Metallofizika 9 (1987) 107-109.

[5] Kokorin V.V., Chernenko V.A., Phys. Met.Metallogr.68 (1989) 111-115

[6] Bondarenko V.A., Zakrevskiy I.G., Kokorin V.V., Chernenko V.A. Materials of II-th Meet. on employment of high pressures for development of new materials. Moscow 25-27 June 1986 p.32.

[7] Kokorin V.V., Martynov V.V., Chernenko V.A. Sowiet Physics Doklady 35 (1990) 379-380.

[8] Kokorin V.V., Chernenko V.A. Phys. Met. Metallogr. 65 (1988) 190-194.

[9] Zakrevskiy I.G., Kokorin V.V., chernenko V.A., sowiet Physics Doklady 34 (1989) $73-74$.

[10] Kokorin V.V., Chernenko V.A. proceedings of All Union conference on martensitic transformations in solid. Kosov, 7-11 oktober 1991 Ukraine (IMP 1991) pp.106-109.

[11] Kokorin V.V., Samsonov Yu.I., Hshanovskiy L.F., Chernenko V.A., Shevchenko O.M. Fiz. Met. Metalloved. 2 (1991) 145-149.

[12] Kakeshita T., Shimizu K., Akahama Y., Endo S., Fujita F.E. Trans. Jap. Inst. Met. 29 (1987) 109-115.

[13] Kakeshita T., Yoshimura Y., Shimizu K., Endo S., Akahama Y., Fujita F.E., Trans. Jap. Inst. Met. 29 (1988) 781-789.

[14] Kakeshita T., Shimizu K., Tanaka R., Nakamichi S., Endo S., ono F., Mat. Trans. JIM 32 (1991) 1115-1119.

[15] Kakeshita T., Shimizu K., Nakamichi S., Tanaka R., Endo S., ono F., Mat. Trans. JIM 33 (1992) 1-6.

[16] Kakeshita T., Mizoguchi K., Shimizu K. at al., Mater. Trans. JIM 33 (1992) 1035-1039.

[17] Kakeshita T, and Shimizu K., Proc. ICoMAT-92, Monterey 20-24 July 1992 (Monterey Inst. for Advanced studies, 1993) pp.475-480.

[18] Smith H.G., Berliner R., Jorgensen J.D., Physica B156\&157 (1989) $53-55$.

[19] Zakrevskiy I.G., Kokorin V.V., Larikov L.N. Rusanova N.I. Chernenko V.A., Metallofizika 9 (1987) 22-25.

[20] Oomi G., Mohammed M.A.K.,Wods S.B., Solid state Commun. 62 (1987) 141-143.

[21] Kadomatsu H., Kurisu M.,Fujiwara H., J.Phys.F.17 (1987) L305-L309

[22] Ono F., Asano M., Tanaka R., Endo S., J. Magnet. Magn. Mat. 90,91 (1990) 73-76.

[23] Kokorin V.V., Cherepov S.V., Chernenko V.A., Phys.Met.Metallogr. 63 (1987) 177-179.

[24] Kolomitsev V.I., Nevdacha V.V., Metallofizika 9 (1987) 132-133.

[25] Doroshev V.D., Kovtun N.M., Molchanov P.I., Synkov V.G., Prib. Techn. Exp. 4 (1984) 195-199.

[26] Estrin E.I. Phase transformations under high pressure. Metallovedyeniye $i$ termicheskaya obrabotka, Moskwa, Metallurgiya (1971) $147 \mathrm{p}$.

[27] Goo E., Sinclair R., Acta met. 33 (1985) 1717-1723.

[28] Otsuka K., Shimizu K.,Suzuki Y, et al. Splawy s effektom pamyati formy. Trans. from Jap., Moskwa, Metallurgiya (1990).

[29] Chernenko V.A., Kokorin V.V.,Proc. ICOMAT-92, Monterey 20-24 July 1992 (Monterey Inst. for Advanced Studies, 1993) pp. 1205-1210.

[30] Webster P.J., Ziebeck K.R.A., Town S.L., Peak M.S., Phil. Mag. B49 (1984) 295-310.

[31] Liakos J.K., Saunders C.A., Phil. Mag. A. 46 (1982) $217-242$. 